\title{
AXEL L. WENNER-GREN, 1881-1961
}

\author{
EMIL W. Haury
}

$\mathrm{F}^{\mathrm{O}}$ OR MORE than two decades anthropology and related disciplines have enjoyed a unique position among the social sciences, the support and encouragement of the WennerGren Foundation for Anthropological Research. Many anthropologists have come to take for granted the Foundation's incalculably important role in promoting the Science of Man. The time is now long past due to look behind the scenes to view the man and the motives which set the Foundation's work in motion.

The invitation to write an appreciation of the late Axel L. Wenner-Gren arouses an immediate question: how did a man who devoted his productive life to industry come to be interested in anthropology to the extent that he was willing to divert substantial resources to its support?

In his own words, the guiding force in establishing the Foundation was the deeply felt need to promote an "appreciation and respect for each other's views and for the values of cultures different from one's own." Surely this feeling arose out of his deep and globally ranging industrial involvements. Facets of his socially inclined thinking are imbedded in a booklet he wrote in 1938 titled Call to Reason. He encouraged pioneering efforts, new approaches; he believed that "risk-bearing areas" were worth supporting and that the best advances could be made through cooperative and cross-disciplinary endeavors. He lived to see the wisdom and the fruits of some of these philosophies.

The Viking Fund, the original name of the Foundation, was established in 1941, a year of international tension. It was the founder's hope that a home in New York would foster close relationships with the nation's scientists and research institutions without, however, limiting its activities to the United States. Nowhere was Axel Wenner-Gren's deep conviction of the global nature of anthropology and the need to bring world-wide scholars together more clearly stated than in his directive to Paul Fejos, the Foundation's Director, to seek out a suitable place for establishing a European headquarters. These were his words: "You will remember that ... what I had in mind was ... [the creation of] a center of scientific activities. Such activities should be planned on the basis of inter- national participation. Conferences and symposia are to be projected whenever possible and practicable on interdisciplinary problems where anthropology could act as the integrating factor. You will bear constantly in mind that my interest is, in this case, man's behavior and motivation ..." Burg Wartenstein in Austria was the answer.

Speaking as an archaeologist, and hopefully therefore for the archaeological fraternity, it is my view that the support pumped into the study of "fossil" cultures restored vigor and gave a new direction to a discipline that was losing ground. I remember well how the award of $\$ 1000$ in 1941 , big money in those days, stimulated a series of studies and launched a level of activity that had consequences in the recipient institution far beyond the expectation and the stated intent of the grants. This was not an isolated case. These "credits" beyond the support of pure research must have been known to the founder and must have given him a sense of fulfillment.

On those occasions when Wenner-Gren found it possible to attend the annual Viking Fund banquets, at which time signal honor was accorded anthropologists, he radiated enthusiasm and absorbed fully the acclaim afforded by the observance, not for his share, I am sure, in the Foundation, but for the high accomplishments in the science that he respected.

Axel Wenner-Gren has left behind him a living monument. Perpetuation of his name was far less important to him than was his abiding conviction that human progress could be aided by supporting the Science of Man. For archaeology and related studies alone this amounted to roughly $\$ 700,000$ over a 20 -year period, or an annual average appropriation of about $\$ 35,000$. More than 225 projects were initiated. These cold figures take on added meaning when it is remembered that for most of the Foundation's history, it was the principal source of support available to the archaeologist. I am certain that as the history of archaeology is written, the solid gains in substance, method, theory, and synthesis witnessed during the mid-20th century will be attributable in large measure to Axel Wenner-Gren and the foundation. 


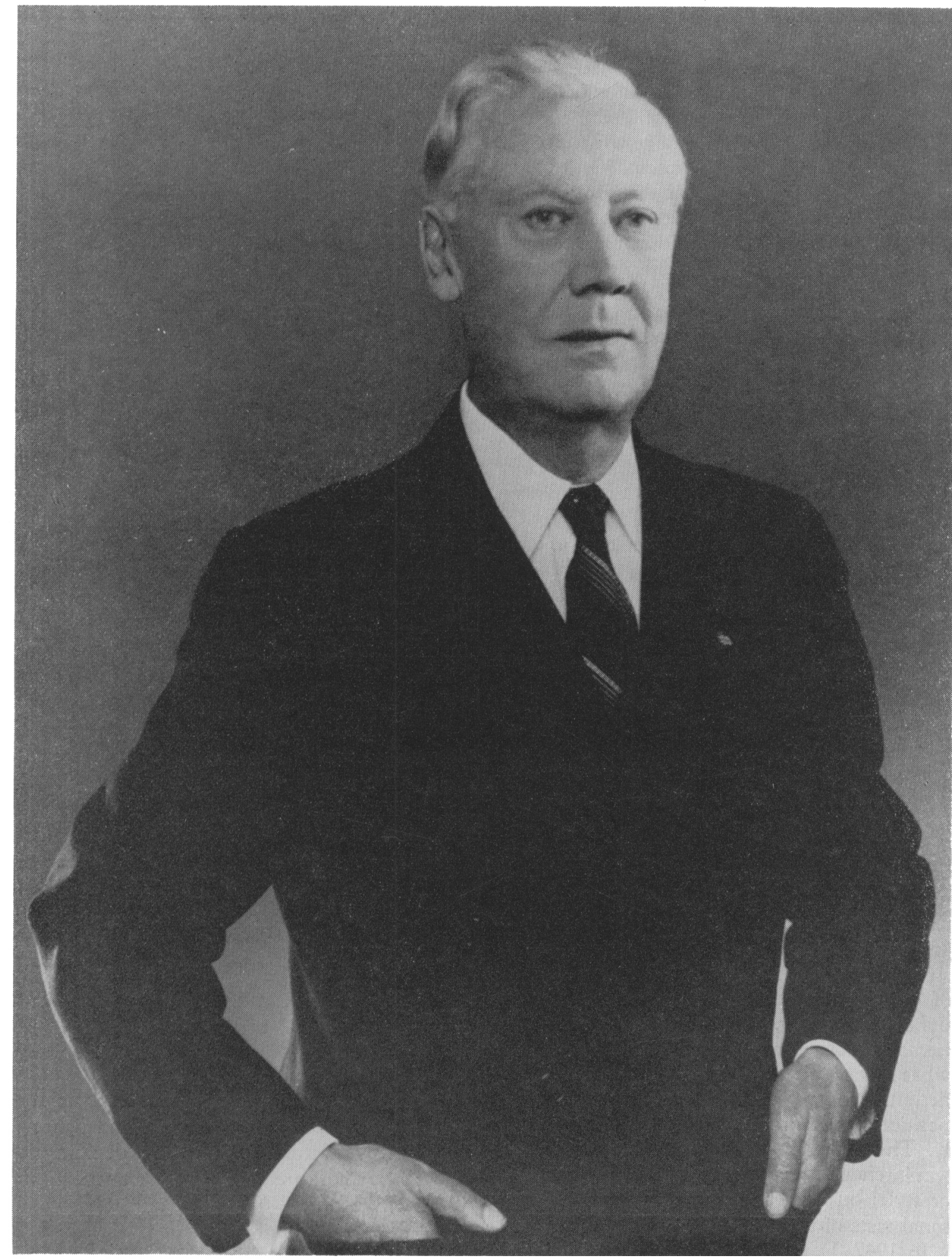

AXel L. WenNER-GREN 